\title{
Aspásia: o AMOr COMO ARMADURA DE ATENAS
}

\section{Fabíola Menezes Araújo, Raíssa Ximenes}

\begin{abstract}
RESUMO
O que Aspásia, hetaira de Péricles, o maior Arcontes de todos os tempos, referida como professora de Sócrates no Menexeno, tem a nos ensinar acerca do nascimento da filosofia e acerca do modo de produção dos diálogos platônicos? Aqui tentamos nos aproximar da solução desta questão tanto a partir das poucas pistas deixadas por esta personagem histórica quanto a partir do Menexemo, diálogo em que Aspásia surge como a pensadora que nomeia a mãe-terra como nutris de todos. Discute-se assim a possível função cívica de Aspásia no advento da chamada Era de Ouro de Péricles, e a pertinência da noção de mãe-terra para unir gregos e estrangeiros em uma época de stasis, conflito na Magna Grécia.
\end{abstract}

Palavras-chave: Aspásia, mãe-terra, koinologia.

\section{ASPASia: lOVE THE ARMOR OF ATHENES}

\begin{abstract}
What does Aspasia, Pericles's hetaira, the greatest Archon of all times, referred to as Socrates' teacher in Menexeno, have to teach us about philosophy's birth, and about Platonic dialogues's production's mode? We try here to approach ourselves to the solution of this question both from the few clues left by this historical character and from Menexemo, the dialogue in which Aspasia emerges as the thinker who names the mother-earth as nurturers of us all. It is discussed the Aspasia's possible civic
\end{abstract}

\footnotetext{
* UFRJ. Doutora em Teoria Psicanalítica pela UFRJ, possui graduação em Filosofia pela Universidade do Estado do Rio de Janeiro (2005) e mestrado em Filosofia pela mesma Universidade (2007). Foi professora de filosofia do Estado e do Colégio Pedro II. confabulando@gmail.com

**PUC-Rio. Mestranda de filosofia, com ênfase em estética e filosofia da arte. raissa.sximenes@gmail.com
} 
function in the advent of the so-called Golden Age of Pericles, and the pertinence of the notion of mother-earth to unite Greeks and foreigners in a time of stasis, conflict in Magna Greece.

Key-words: Aspasia, mother-earth, koinologia.

\section{INTRODUÇão}

Uma vez que as mulheres não tinham cidadania na Grécia Antiga talvez se afigure como um equívoco o que tentamos fazer aqui, a saber: apresentar Aspasia como capaz de uma atuação política relevante. Em sua atuação amorosa, Aspasia chegará a ser referida como professora de Sócrates, além de mulher de Péricles. Nós a tomamos como uma força capaz de nutrir com sua presença amorosa o fundamento da construção da Atenas que deu à luz à filosofia socrática. A seguinte dúvida nos intriga: teria Aspásia, uma estrangeira, de fato conseguido se fazer ouvir por Sócrates de modo a dever ser reconhecida por este como sua professora no que tange à retórica no Diálogo o Menexeno, ou terá a menção do filósofo a Aspasia meramente irônica? Isto que se afirma em um dos diálogos cuja autoria é mais investigada, o caráter magistral de Aspasia teria sido de fato fruto da relação entre o jovem Sócrates e a mulher do estratego que terá levado a cidade de Atenas à estatura de a maior expoente de todas as épocas, ao menos no tocante à filosofia e à escultura? Nós que ansiamos por fazer ouvir a mãe-terra como faz ouvir Aspasia no canto que esta enuncia no Menexeno talvez possamos discutir isto que pode ser sinalizado como um ponto histórico de concórdia para muitos: ter sido o marido de Aspásia - Péricles - o arconte eleito na Atenas de 461 a.C. a 429 a.C, época em que este teria feito mudar até as leis a fim de poder ser reconhecido como marido de Aspasia, a estrangeira.

Para que possamos realizar uma leitura a um só tempo consistente, e capaz de evidenciar como se terá dado o amor de Pericles, e de Sócrates, pela protagonista da obra estudada será oportuno nos situarmos no contexto político em que a oração fúnebre que é o discurso de Aspásia terá tido lugar. Como terá sido o que chamamos de 
último resplandecer da deusa grega ${ }^{1}$ pela voz desta que morreu um ano antes de Sócrates (470a.C. - 400a.C.), em uma época símile em pesares à nossa, e em que o discurso de Aspásia tem lugar? Pelo contexto de pêsames em que Aspasia brilha como especialista da pratica de rememorar aqueles que não mais estariam entre nós, mas que bravamente lutaram, e que, no post-mortem, merecem a glória, não ousamos duvidar do papel histórico de Aspasia no contexto histórico estudado. Pois bem: É um enterro, todos choram, mas Aspásia canta. Mas o que exatamente ela canta?

\section{A ORAÇão No MENEXÉno}

Sobre a oração fúnebre de Aspásia temos a qualificação de ser capaz de encantar. Sócrates diz, talvez jocosamente, ter ficado "maior", "mais belo" e "mais nobre" do que antes de escutá-la, o que deve ser lido como uma grande exaltação à arte retórica, haja visto ser Sócrates conhecido pela feiura e pela baixa estatura. Depreende-se tratar-se de um transe, isto ao que nos leva o discurso que vem a ser encantador como deve ser uma obra de arte segundo as Leis (559e). 0 efeito do discurso sobre Sócrates é de ter sido convidado a habitar na "ilha dos bem-aventurados" (235c). Isto, questionamos, teria sido obra exclusiva da oração de Aspásia, isto é, de seu efeito discursivo sobre os ouvintes?

\section{QUEM Foi ASPásia?}

Irmã de Alcebíades, "o velho", teria ido para Atenas ainda jovem com a família. Estrangeira, viveu em concubinato com Péricles até que este viesse a se divorciar. Cedendo a ex-mulher a outro homem, Péricles pôde usufruir de seu casamento com Aspásia livremente - casamento que ficou conhecido como muito feliz: uma anedota diz que Péricles cumprimentava-a com um beijo amoroso duas vezes por dia.

\footnotetext{
1 Defendemos, em outro artigo, a hipótese de que Atenas teria sido uma das deusas remanescentes do Matriarcado Minoico. É possível que este matriarcado, existido na Ilha de Creta mil anos antes do surgimento dos primeiros pensadores gregos, tenha sido o primeiro lugar de aparecimento das deusas que farão parte do panteão grego. Esta tese é defendida no artigo intitulado "O Matriarcado Minoico (Keftiu) e a arcaica ausência de fronteiras entre arte, filosofia, política e religião", no prelo da Revista Arethe.
} 
Na qualidade de hetaira (companheira), Aspásia ficou conhecida por exercer grande liderança sobre o marido. Além disto, ela teria fundado uma escola de hetairas em função da qual recebeu reputação de excelente professora. Como já comentado, Sócrates teria sido um de seus alunos mais famosos, mas há dezessete testemunhos (DUESO, 2006) que afirmam que ela, mesmo sendo esta prática contra as leis, teria dado aulas ainda para muitos homens. A favor desta perspectiva temos nada menos do que os testemunhos de Péricles (495/492 a.C. - 429a.C.), Sócrates e Lísicles - três das personagens mais reputadas de Atenas.

"Era (também) perita em economia doméstica e no aconselhamento de casais, segundo Xenofonte" (BERQUÓ, p. 41). Não que o reconhecimento do caráter ilibato de Aspasia seja uma unanimidade:

"Plutarco afirma que Aspásia foi acusada de impiedade (asébeia) e de arrumar encontros de Péricles com mulheres livres (Vida de Péricles, XXXII). 0 acusador (conquanto) era um poeta cômico - Hermipo. Aspásia teria sido defendida pelo próprio Péricles, sendo absolvida depois que este chorou perante os jurados (idem, XXXII)." (Idem, p. 31, pequenas alterações nossas).

Com Péricles Aspasia teve um filho considerado bastardo. Antes de morrer da peste ${ }^{2}$ que dizimou parte da população grega, pela qual viera a morrer também seus outros dois filhos, contudo, o general grego lutou para mudar as leis, a fim de fazer com que o seu filho com Aspasia se tornasse o seu legitimo herdeiro, e conseguiu.

Não é possível comprovar uma ocorrência dramática na atividade docente de Aspasia: Nada menos do que a Guerra do Peloponeso (431- 404 a.C.) teria tido lugar em função de terem sido raptadas duas hetairas formadas por ela (apud. BERQUÓ, 2016). Conta-se que esta Guerra teria tido lugar em virtude de os atenienses primeiro terem roubado Simeta, uma hetaira de Megara, ou seja, dos megarenses, e, em retaliação, estes últimos terem raptado as duas hetairas de Aspasia. Se non è vero, è bene trovato.

\footnotetext{
2 A mesma que teria sido adiada por Diotima em dez anos segundo Platão. 0 Banquete, $210 \mathrm{~d}$.
} 
Ressaltando a questão da habilidade retórica de Aspásia, Sócrates relata a Menexeno que esta tinha talento para o improviso. Diz que não há dificuldade alguma em improvisar-se um discurso mas que se deve possuir talento para tal. Nas palavras do filósofo:

Não há de se admirar, Menêxeno, se eu for capaz de falar bem, pois tive, justamente, uma professora nada fraca na arte da retórica, e que preparou excelentes oradores, entre os quais se destaca o mais distinto dos Helenos, Péricles, filho de Xantipo. (PLATÃo, 2015, 235 e, p. $290^{3}$ ).

Menéxeno conclui que Sócrates só poderia estar falando de Aspásia. 0 filósofo ateniense refere-se a ela como sua professora na arte da oratória, ressaltando ser natural a quem teve tão boa professora falar bem, e isto até de maneira improvisada. Além disto, diferentemente de quem obteve educação oratória com outro professor, e que somente dentre os atenienses poderia obter sucesso, Aspasia teria conseguido, segundo Sócrates, ressoar e tomar vulto até mesmo perante os peloponesos. Com isto, o discurso de Aspasia irá receber o mais forte elogio que pode um discurso receber: o de até no estrangeiro ressoar em beleza, sendo causa de constante admiração.

É possível nos questionarmos acerca do fato de haver certa potência no contra-senso de Aspásia ter sido julgada pelo descumprimento das leis atenienses e, mesmo assim, ter conseguido exercer as funções educativas gregas de maneira tão extraordinária. Talvez a fala de Sócrates possa esclarecer um pouco as transgressões de Aspásia como as de mulher, a um só tempo, fora e dentro de sua época:

(...) como irmãos nascidos de uma única mãe, não nos consideramos reciprocamente escravos nem senhores; a igualdade natural de origem nos obriga a procurar a igualdade política, segundo a lei, e a prática de não reconhecer outra superioridade além da conferida pela fama de virtude e sabedoria o que nos causa. (PLATÃo, 239a, pequenas modificações nossas)

\footnotetext{
3 Pequenas alterações de tradução nossa, assim como nas demais citações do Menexeno que se seguirão.
} 
Aspásia é a exceção à regra, o que se confirma através de e no que unicamente se justifica pela sua sabedoria e virtude, transmitidas e tornadas evidentes em sua retórica. Em 347a há uma sentença reputada à Aspasia que confirma os argumentos apresentados até aqui: "Todo conhecimento dissociado da justiça e das demais virtudes é apenas astúcia, jamais sabedoria" (PLATÃO, 2015). A maior potência de Aspasia consiste, pois, em ter podido colocar a justiça para além das leis criadas pelos homens; e talvez aí e por isto tenha tido nascimento a capacidade de "enfeitiçar" a todos os que prestaram a ela reverência.

Tragamos um pouco do contexto dramático em que o diálogo tem lugar - Sócrates diz que Aspasia, no dia anterior, tinha pressa em saber se proferiria uma oração fúnebre capaz de tocar o coração de todos. Improvisadamente, teria ela dito justamente as palavras que o filósofo ateniense declama a Menéxeno no diálogo homônimo ${ }^{4}$. Parte dessa oração improvisada composta por Aspasia já era, segundo crê Sócrates, parte de um discurso previamente proferido por Péricles. Sócrates, por sua vez, receia repetir a oração e causar aborrecimentos à professora, que o filósofo nomeia como "severa".

\section{ASPásia E O DiSCURSo QUE RECORRE à "MãE-TERRA"}

No que Aspasia elogia (paramytoumenos, $\pi \alpha \rho \alpha \mu v \theta$ oú $\mu \varepsilon v o \varsigma$ que significa literalmente transformar alguém em mito, 237a) a nobreza

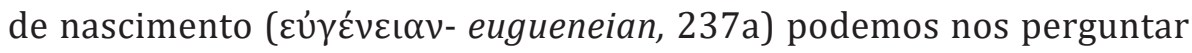

4 Sócrates diz que Péricles também a havia submetido, no quesito oratório, a perguntas na mesma ocasião. Isto pode soar como um contracenso para quem supõe que o diálogo teria sido na verdade escrito em 380 aC..

Um elemento passível de ser trazido a tona é a perspectiva de que, segundo a lexis platônica - concepção defendida com brilhantismo por Benoit em "A odisseia de Platão. As aventuras e desventuras da dialética" (2017) - não ser possível situar o diálogo em questão como autêntico. Isto é, para o autor da única proposta autenticamente brasileira-uruguaio, em princípio seria o Menexeno um diálogo apócrifo. A perspectiva de não ser possível datá-lo - como acontece a muitas outras obras (a exemplo do Ion e das Epinomis) (BENOIT, p. 563) - para nós, no entanto, soa como um enigma. Que outro autor poderia tecer um diálogo onde Sócrates a um só tempo, se apequena e se engrandece frente a uma mulher de modo tão surpreende? o que teria quisto este outro escritor ao trazer Aspásia como professora capaz de engrandecer o próprio Sócrates e, quem sabe, ser maior que a própria filosofia?

Revista Páginas de Filosofia, v. 9, n. 2, p. 19-34, jul.-dez. 2020 
se se trata, por exemplo, de instalar uma separação radical entre os que nascem nobres e os que nascem plebeus. No entanto, veremos ser esta uma resolução rasa: pois serão de nobre nascimento todos aqueles nascidos na mãe pátria.

No mesmo parágrafo, à expressão "no que a linguagem se mostra"

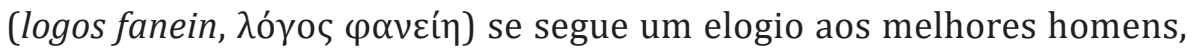
os nobres. Cito: "elogiemos os melhores corajosos que principiam corretamente" (ortos archaimeta andras agatous etainontes, ó $\rho \theta \tilde{\omega} \varsigma \alpha \dot{\alpha} \rho \xi \alpha \dot{\mu} \mu \varepsilon \theta \alpha$

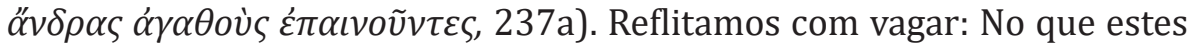
seres corajosos se destacariam dos demais? E a resposta: na inteligência

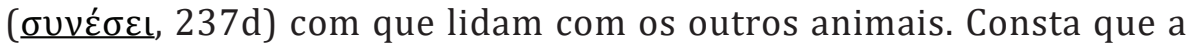
inteligência que tem aí lugar é um poder ser junto aos outros animais, um poder ser-lhes íntimo. E isto significa também poder ser na justiça e junto aos deuses (oh sinesei te uperechei ton alon kai diken kai teous

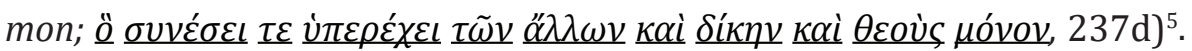

É possível já nesta sentença ser antecipado o aparecimento do termo nous, que aparecerá fulgurante nos 241e; $247 \mathrm{~d} ; 248 \mathrm{c}^{6}$. 0 que neste nous se mostrará não se dará sem a linguagem; isto pelo menos é

5 Diz Aspasia, em outra tradução: “(...) a nossa (terra) se conservou virgem e pura de feras, e, se entre todos os seres vivos escolheu e gerou o homem, superior aos demais em inteligência, e o único que venera a justiça e as divindades" (237e), perguntamos nós agora - por que é então que aconteceu de o mar e a terra ficarem tão poluídos?

6 O nous é o pensar entusiasmado, isto é, pleno de deuses. É preciso dize que, aqui, buscamos nos situar em um nous já de início feminino, diferentemente de Bertrand Husserl (apud. BLANCO (2009)). Para tanto, foi necessário que investigássemos o nous junto a uma mulher, que quis o destino que fosse Safo. Esta segunda pesquisa ainda em andamento, será pu-blicada em momento oportuno sob o título de "0 amor em Safo." Podemos ainda assim sinalizar, aqui, para a disponibilidade de que seja encontrada uma forte ressonância de cunho semântico entre o nous em que se situa Safo e o nous em que se situa Aspasia, Cf: em Safo, 2003, temos as seguintes

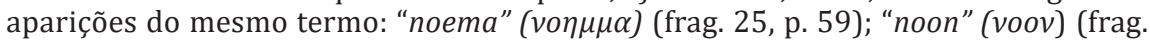
86, p. 111); nun, (vvv) (frag. 14, p. 143); noema, (frag. 6, p. 159) ; e, finalmente , [n] on ([v] $\omega v)$ (frag. 10, p. 41). Cabe sublinhar, ainda assim, que o âmago de todas estas pesquisas seja a possibilidade de pensar e valorizar um nous que se saiba e se queira feminino. Cabe sublinhar que o nous que buscamos se realiza, antes e sobretudo, como um órgão musical ou ainda um lugar onde os deuses puderam e ainda podem habitar. Neste sentido, cabe, finalmente, antecipar também a descoberta do keinos como um outro lugar ou um outro âmago onde o divino pode acontecer. Temos este mesmo desdobramento intuitivo - que aponta para a existência de uma forte relação fenomenal entre o nous e o keinos - tanto em Safo (Cf. 2003, 31, p. 21) quanto na Ilíada de Homero quanto nos povos Yanomami (Cf. Kosmos Society, 2018).

Revista Páginas de Filosofia, v. 9, n. 2, p. 19-34, jul.-dez. 2020 
o que se pode presumir da expressão "no que a linguagem se mostra" já referida acima. E é nela que ressoará um nous capaz de se orientar para o certo. Será nada menos do que junto a este nous que principia todos os melhores. Cito:

Pois não foi a imortalidade que tinham desejado aos seus filhos, mas a excelência e a glória, que obtiveram e que são os maiores bens. Não é coisa fácil para um mortal ver acontecer ( $\kappa \alpha \tau \dot{\alpha}$ voũv) tudo como é seu agrado. Suportando a infelicidade como homens, passarão verdadeiramente como pais de filhos que foram bravos como eles mesmos são $[247 \mathrm{~d}]^{7}(. .$.$) "Pois quanto o tempo da nossa existência chega ao seu$ fim, é o momento mais admirável para a humanidade, pelo que as homenagens são mais próprias que os lamentos. É tomando cuidado das nossas mulheres e dos nossos filhos, preocupando-se em alimentá-los e ocupando assim os seus pensamentos ( cerão este golpe de sorte e serão capazes de viver mais nobremente, mais rectamente e mais em harmonia com os nossos desejos $\left.{ }^{8} \cdot[248 c 7]\right)$

Aí o nous é um pensamento conciliador, a partir do qual "a excelência e a glória" e um "viver mais nobremente (...) mais em harmonia com os nossos desejos" podem vir a ser. A morte tem importância: é capaz de claro ao nous que nossas máximas possibilidades nascem a partir do cuidado passível de ser junto com o outro, "com as nossas mulheres e nossos filhos."

Ao final do primeiro parágrafo de sua fala, Aspasia, em sua destinação, convidará a todos mais é à celebração: "Celebremos para

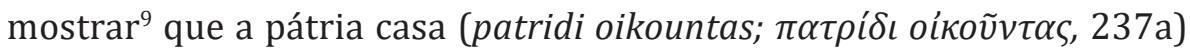
é a mãe terra (tes Choras; $\tau \tilde{\eta} \varsigma \chi \omega ́ \rho \alpha \varsigma, 237 a)$. Diz ainda que é “'porque' é justo (dikaiotaton; $\delta \iota \kappa \alpha \iota o ́ \tau \alpha \tau o v, 237 c$ ) que é preciso conferir à mãe-terra por si o lugar primeiro (primeiro/a da mãe mesmo; $\pi \rho \tilde{\omega} \tau o v ~ \tau \dot{\nu} v$

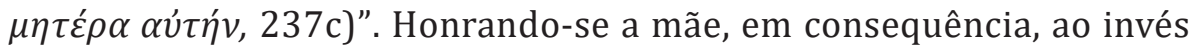
de choro, temos a honra de seus descendentes.

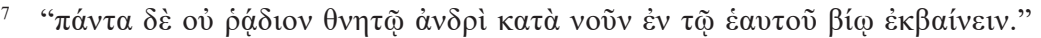

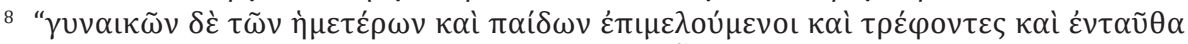

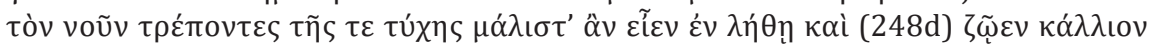

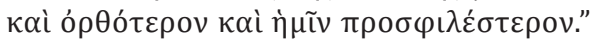

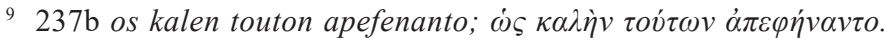

Revista Páginas de Filosofia, v. 9, n. 2, p. 19-34, jul.-dez. 2020 
Podemos agora esclarecer o que estaria em jogo com a noção de nobreza já referida: Trata-se de salvaguardar o lugar de boa gênesis de todos aqueles que se fazem nobres em virtude de saberem respeitar a mãe terra. Em outras palavras, o discurso faz notar a nobreza, a chamada "eugenia", não como apelo a uma irmandade de sangue, mas a uma irmandade de sentidos da existência, onde a mãe terra é que capaz de provocar a inteligência, tanto de lida com os outros animais, quanto com os deuses.

\section{Aspásia na "Boca" de Sócrates}

Na oração fúnebre transmitida por Aspásia a Sócrates temos, assim, a noção de uma Mãe-pátria única, passível de ser melhor chamada de mátria ${ }^{10}$, e que ressoa como um lugar semelhante ao do originário-trancendental-a-priori tão em voga na filosofia contemporânea. É por ser a mesma mãe para todos que a mãe terra ocuparia este lugar, do a priori. É como reflexo deste amor à mátria que surgiria, ademais, a própria paideia grega.

\section{A Oração de Aspásia e a “bela morte” do herói.}

A oração fúnebre de Aspásia cumpre com o dever de reconfigurar a questão da bela morte heroica (tão cantada por Homero) em solo ático. Pode-se concluir ser melhor morrer em kléos (glória) do que viver na covardia. Na covardia não se vive, apenas se padece. Isto também ressoa com clareza do diálogo comentado: na Atenas clássica de Sócrates ainda há a influência dos atos míticos sobre a formação social do povo e as guerras. 0 discurso de Aspásia tem o poder de fazer com que os vivos queiram imitar os mortos que morreram lutando. Enaltecendo a areté (honra) dos guerreiros (236e), ela pôde tornar

10 Como Caetano Veloso propõem: "Se você tem uma idéia incrível/ é melhor fazer uma canção./ Está provado que só é possível filosofar em alemão (...) A língua é minha pátria/ E eu não tenho pátria, tenho mátria/ E quero frátria." (1984). Acreditamos que esta música seja, do que já foi escrito, a que guarda mais afinidade com o discurso de Aspasia, por ela falar em nome da mátria (que no discurso dela receberá o nome de mãe terra) e por ela falar em nome da fátria (que no discurso da professora grega receberá o nome de irmãos). Veremos que mesmo aos estrangeiros Aspasia chamará de irmãos. 
nítido que alguns homens se tornam bons por morrerem em nome da sua cidade, e da deusa Atenas.

\section{ASpasia para a Contemporaneidade}

Atenas é a terra que submeteu a barbárie à civilização. Isto contem um caráter contraditório: pois, se, por um lado, a partir da herança grega o homem adveio com um poder de domínio sobre a physis incrível, por outro lado, este mesmo domínio fez dele um escravo da técnica. Armou homens belicamente. Porém, a maior armadura de todas, que é a relação estreita com o plano divino, talvez tenha se perdido durante estes pouco mais de dois milênios de patriarcado. De onde vem a chaga poderá vir a cura?

Aqui defendemos Aspasia como portadora de uma retórica capaz de abrir o coração mesmo do inimigo mais ferrenho.No discurso de Aspásia, diferente de na tradição filosófica em geral, temos em destaque o

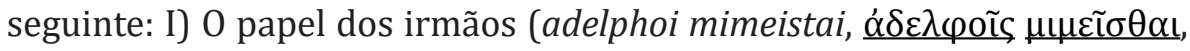
236e), isto é, da fraternidade enquanto capaz de curar danos; II) a mímesis reerguida ao apreço de todos, se mostrando imprescindível à ética, e, III) o poder ter a virtude como imitável, e não simplesmente ensinável ${ }^{11}$.

Diferente dos filósofos que costumam enaltecer (sobretudo Platão) o lugar do eromenos e do erastes, isto é, do jovem aprendiz e do adulto responsável pela inserção deste no cenário civil ou intelectual, respectivamente, Aspásia privilegia a figura dos irmãos. Mortos, são exemplos a serem seguidos. Ao morrerem, deixam como legado suas trajetórias de coragem. E por isto não podem deixar de ser honrados. Não apenas porque isto seria ímpio mas porque seria desonroso para quem está vivo. A questão que mais ressoa no diálogo, nesta medida, talvez seja esta: haverá amor mais autêntico do que o dos que se destinaram a morrer pela terra? A reflexão é direcionada para a seguinte resolução: Se os irmãos que morreram, o fizeram lutando para manter viva a chama capaz de salvar o sentido da terra, e por isto nós os glorificamos.

Há uma dialética interessante na oração de Aspasia: porque se há, por um lado, a necessidade de salvaguardar o valor ético do ato de

\footnotetext{
11 Sugerimos que esta III deve ser lida não como uma causa mas como uma consequência da premissa de número 2 .
} 
morrer daqueles que morreram lutando por nós, por outro lado, há um convite à reflexão sobre o sentido da morte - se mesmo o estrangeiro é meu irmão - por que ele haverá de morrer sob minhas mãos?

Aspasia termina por aquiescer o exemplo no campo da ética: segundo sua fala, na imitação é que deve ter lugar o aprendizado dos hábitos e costumes melhores para que a comunidade possa ser plenamente divina.

Por tudo isto, defendemos ser Aspasia além-homem ${ }^{12}$ : ela solicitará a todos que mantenham em seus corações, ao invés de vingança, apenas o sentimento de condolências e de celebração. E isto também pelo estrangeiro, irmão que também morreu lutando. Canta Aspasia um canto capaz de restituir ao sagrado seu justo teor ético: Convida todos ao fraterno. De sua retórica, nasce um dos únicos destinos capazes de fazer jus à armadura de Atenas: para o qual há e pode haver o que há de mais universal, entidade a que todos os povos podem e devem prestar reverência sem medo de ser felizes: a mãe terra. Assim, ela nos destina a ser a partir desta mãe, celebrando-a sempre que possível.

Tampouco haverá coincidência em podermos falar agora em nome daquela em virtude da qual são gerados o Baobá e a Acácia, assim como todos que nascemos e perante a qual urge apenas uma mensagem : a que se faça capaz de cuidar dela.

Retomando: afinal, por que e de que modo Aspasia pôde falar em nome de todos? 0 argumento fundamental de seu canto mortuário, e que talvez faça deste canto mais potente do que a própria filosofia, é se postar ele como porta-voz da mãe terra. Por isto é necessário que o seu discurso ressoe até os confins: Trata-se, finalmente, de uma mulher falando em nome de um saber genuíno que é o de amar o solo em que se pisa. Por isto devemos todos aprender a ouvi-la.

Como pontuado de inicio julgamos também que a oração a que Aspasia dá voz só pôde vir a ser tomada como um ato de fala porque foi, antes, a deusa, Atenas, quem quis ser ouvida na canção a que ela deu voz.

12 Referência ao conceito nietzscheano de além-homem - über-meschen (traduzido por sobre-homem e por super homem) - o próprio sentido da terra. Cf Marton, 1990, p. 11. 
Antes - foi esta grega porreta ${ }^{13}$ que pôde se afirmar ao se afinar com aquela entidade feminina a partir da qual e através da qual a boca do grande fundador da filosofia ocidental - Sócrates - tenha talvez ficado pequena. 0 mestre ele próprio assevera esta possibilidade interpretativa ao prestar-se a múltiplas reverências à senhora de Péricles ${ }^{14}$ que tanto lhe ensinou ${ }^{15}$. 0 discurso parece ressoar como raios de luz para todas as Eras: talvez porque nele Aspasia tenha procurado enunciar tão bem não tanto o Bem, mas as condições de possibilidade para um recomeço: que possamos em nome da mátria guerrear menos e amar mais.

Que amor é este em nome do qual fala a educadora grega? Agelceia (Agelkeia), Atenas, líder protetora do povo é quem se anuncia: Que morram todos, mas que não morram desonrados. Aos irmãos na mátria ela clama. Para que possamos proteger uns aos outros, mais que tudo é preciso união, e, para isto, até a morte deve poder servir ao discurso. E para que este possa se fazer amável, amante, capaz de espalhar apenas o amor, ela toma recurso no sentido da terra.

\section{ConCluSÃo: O AMOR NA FILOSOFIA EM CONTRASTE AO AMOR do DISCURSO DE ASPASIA}

Muito embora a palavra "filosofia" nos remeta, etimologicamente, a um dos sentidos originários da palavra amor ${ }^{16}$, e talvez seja esta palavra capaz de nos colocar no âmago de um dos sentidos extraordinários da palavra 'amor', contam-se entre os melhores os filósofos que se ativeram a pensar o amor enquanto um acontecimento necessário ao pensar, isto é, o amor como um acontecimento originário ${ }^{17}$, necessário

13 Pedimos aqui uma licença poética para uso do termo "porreta", que nos parece perfeitamente afinado com um outro legado fundamental, a saber: das mulheres nordestinas.

14 É relativamente conhecida a perspectiva de que Péricles ele mesmo só virá a assumir a função simbólica de que se revestirá em função da proeminência sapiencial de Aspasia.

15 Outra a quem ele reverencia durante quase toda a sua existência é Diotima, esta por ter-lhe ensino a amar, Aspasia por ter lhe ensinado retórica.

16 enquanto amor ao saber.

17 Alguns poucos filósofos pensaram o amor como um fenômeno ontológico, e merecem destaque Platão, Santo Agostinho, Hegel, e Nietzsche. 0 primeiro na medida em que a personagem Sócrates recomenda a palavra de Diotima que, por sua vez,

Revista Páginas de Filosofia, v. 9, n. 2, p. 19-34, jul.-dez. 2020 
a todo e qualquer vir a ser. Na promoção de uma política da fraternidade, como enunciado pelo discurso de Aspasia, o amor soa como um a priori inescapável.

Em nossa época, nos acostumamos a limitar o pensamento ao postulado do 'ou pensamos, ou amamos'. Com isto, nos acostumamos a deixar de lado o que mais humano nos parece, a saber: o poder de amar, e de amar o conhecimento que se chama filosofia. Desconfiamos que a conclusão a que facilmente se chega na metafísica moderna "que o pensamento não se ama e o amor não se pensa" tem levado a humanidade apenas para o cadafalso ${ }^{18}$. Isto tão somente porque os pensamentos que têm origem no patriarcado parecem insistir no ensinamento de que tanto o amor feminino quanto o pensar feminino seja de menos valia, ou ainda que todo e qualquer pensar não requer, antes, amor para vir a ser.

\footnotetext{
situa o amor como participação (metaxei), "parte da dialética erótica ensinada pela sacerdotisa (209e ss), consistindo esta de insights cada vez mais desparticularizantes da noção de belo implicada no amor, até a visão do verdadeiro objeto do amor, o belo ele mesmo. Uma vez aniquilado o terrível e ameaçador Amor, a felicidade dos amantes deixa de ser quimérica e torna-se perfeitamente alcançável" (FRANCO, 2018, p. 90, pequenas alterações nossas). Já segundo Hannah Arendt, para Santo Agostinho, enquanto o amor acontece, amplia-se a alma (apud. CARNEIRO, 2007). Se com Hegel o amor terá um estatuto ontológico provisório, que perde tão logo o amor cristão se mostre impossível de ser exigido (apud. SAFATLE, 2008), em Nietzsche o amor talvez perca lugar para a vontade de poder porque e na medida em que o fenômeno histórico apresenta-se como encaminhamento da forma cristã de amar, para a qual apenas uma forma de amor talvez valha a pena (apud. BITTENCOURT, 2011). Mas, perguntemos, no pensamento da vontade de poder são lembrados aqueles que optaram por não ter poder?

18 Na nota anterior situamos os principais filósofos que se ativeram ao amor enquanto questão fundamental. Ainda assim, a seguinte questão atravessa o nosso texto: Não será a metafísica ocidental que estará errada ao decretar a impossibilidade de que o logos, isto é, a linguagem se atenha ao amor como uma condição prévia a todo e qualquer pensar? No caso de a resposta ser afirmativa, declaramos que esta metafísica está falida, pois o amor é condição prévia senão de todo e qualquer ente, certamente é condição do ente que somos. Neste sentido, necessário é inventarmos outros modos de ser e de pensar. Aqui se insere o noema feminino, como possibilidade de descoberta de outros modos de ser que já partem de um diálogo amoroso com toda e qualquer metafísica, e isto a partir do norte da matrística como lugar de acontecimento do divino em nós. (Cf. MATURANA, 1993)
}

Revista Páginas de Filosofia, v. 9, n. 2, p. 19-34, jul.-dez. 2020 
Quanto mais o homem ocidental despreza o feminino, mais o amor soa dispensável; e mais o feminino vem a ser desprezado. Mesmo no que é dito filosoficamente sobre o amor, o feminino não parece ser tido como imprescindível ao advento do mesmo. Defendemos não ser por conta de o amor não ser um acontecimento ontológico que, por hábito, se nutra por ele desprezo na Academia. 0 problema não é do amor, mas da ontologia contemporânea que parece prescindir dele. A ontologia que tem lugar durante o patriarcado não presa o amor, e podemos nos perguntar em que medida este patriarcado exista sem o amor, ou se não é o caso desta ontologia apenas relega-lo a um segundo plano ou a um plano de menos valia. Desconfiamos de que o que esta nossa Era faz reiteradamente é esquecer a condição prévia de que, para que um ser humano cresça, é preciso muito amor; e que necessário ao advento do pensar é, igualmente, o amor. Defendemos que isto se tenha dado em função de uma vontade de poder de alguns conglomerados de erigir-se como a única potência capaz de lidar cientificamente com o que quer que seja.

Sob esta ótica, contemporaneamente, mesmo no que é dito sobre o amor, por hábito, é esquecido que ele é um manancial mas mais para a ordem do imprevisível. Reflitamos: será que é justamente necessário renascermos para o imprevisível que há no amor? Isto talvez seja possível a partir da oração fúnebre de Aspasia. Podemos pois finalmente perguntar: Poderia ter surgido a filosofia sem o amor que chegara a emanar da figura de Aspasia? Mas, antes de mais nada, voltemos à questão - quem é Aspásia?

Aspasia é reflexo de uma terra tão amada pelas deusas não merecerá ser louvada por todos os que nela habitam. É improvável que até os estrangeiros que forem tocados por esta sabedoria não terminem por decidir largarem as suas armas. Além dos ritos fúnebres, a oração é "tributo da palavra". Os autóctones, oriundos da terra Atenas, os que descendem dos mais honrosos cidadãos, devem poder aprender a louvar, no logos, primeira e mais propriamente, mais do que a pátria materna, a mãe-terra, a mátria. 


\section{REFERÊNCIAS}

ARAUJO, Fabíola. o Ser-aí na Analítica Existencial de Ser e Tempo. Dissertação: UERJ, 2007. Disponível em : <https://www.academia.edu/s/be0a7ebb5b/o-ser-ai-na-analitica-existencial-de-ser-e-tempo-por-fabiola-menezes-de-araujo $>$. Acesso em $31 / 10 / 2018$.

BERQUÓ, Thirzá AmaraL. Aspásia de mileto: mulher e filosofia na Atenas Clássica I, In.: Filósofas: a presença das mulheres na filosofia. [recurso eletrônico] / Juliana; Pacheco (Org.) -- Porto Alegre, RS: Editora Fi, 2016.

BENOIT, Hector. A Odisseia de Platão: as aventuras e desventuras da dialética. São Paulo: Annablume, 2017.

BITTENCOURT, Renato Nunes. Nietzsche e a idiotia divina de Jesus. Kriterion, Belo Horizonte, no 123, Jun./2011, p. 105-119. Disponível em: <http://www.scielo.br/scielo. php?script=sci_arttext\&pid=S0100-512X2011000100006 > Acesso em: 31/10/2018.

BLANCO, Clara Eugenia Rojas. "La perspectiva de género: noema y nóesis de la epistemología feminista.” Nóesis. Revista de Ciencias Sociales y Humanidades 18, no. 35 (2009).

CAMARA, Bruna. Menêxeno: Tradução, Notas e Estudo Introdutório. Dissertação. USP. 2014.

CARNEIRO JUNIOR, R. A. O amor na política: um diálogo entre Hannah Arendt e Santo Agostinho. História: Questões \& Debates, Curitiba, v. 46, n. 1, p. 31-50, jan./jun. 2007.

DUESO, José Solana. Aspasia de Mileto: la metáfora y el personaje. 2008. Disponível em: <https://www.academia.edu/11842982/Aspasia_de_Mileto_la_met\%C3\%A1fora_y_ el_personaje >. Acesso em: 15. set. 2015.

FRANCO, Irley. O Sopro do Amor: um comentário ao discurso de Fedro no Banquete de Platão / Coleção Nós Gregos. Eles Modernos. Org. Irley Franco e Elsa Buadas. Rio de Janeiro: Palimpsesto, 2006.

Platão antitrágico: a crítica à poesia nos livros II e III de a República. 0 que nos faz pensar [recurso eletrônico] : cadernos do Departamento de Filosofia da PUC-Rio. Vol. 1, n. 1, (1989)- . - Rio de Janeiro : Pontifícia Universidade Católica do Rio de Janeiro, Departamento de Filosofia, 1989-v. jan-jun. 2018.

GATELL, Rosa Rius. Introdución - Las Filósofas de Gilles. Ménage. In: MÉNAGE, Gilles. Historia da las Mujeres. Filósofas. Barcelona: Herder Editorial, 2009, p. 11- 41.

HOMERO. A Odisseia. Três volumes. trad. de Donaldo Schüler. Porto Alegre, RS: L\&PM, 2007. KOSMOS SOCIETY. An online community for Classical Studies. Homeric Greek | Odyssey 1.169-177, part 2: Epiphanies and Athena's travels. 2018. Disponível em: <https:// kosmossociety.chs.harvard.edu/?p=40196> Acesso em: 31/10/2018.

Revista Páginas de Filosofia, v. 9, n. 2, p. 19-34, jul.-dez. 2020 
MATURANA, H. e VERDEN-ZÖLLER, G. Amar e Brincar - fundamentos esquecidos do humano. São Paulo: Palas Athena Editora, 2011, 3a edição. 263 páginas. ISBN 978.7242-048-7. Original publicado em 1993, em Santiago, Chile..

PLATÃO. Menexeno ou Oração Fúnebre (§234a- §249e). Trad. JOSÉ COLEN, UNIVERSIDADE DO MINHO. Gaudium Sciendi, Número 7, Janeiro 2015. Disponível em: <http:// www2.ucp.pt/resources/Documentos/SCUCP/GaudiumSciendi/Revista_Gaudium_Sciendi_n7/16.\%20Menexeno\%20ou\%20a\%200ração\%20Fúnebre\%20revisto.pdf> Acesso em: $31 / 10 / 2018$.

Symposium. In: BURNET, John (ed.) Platonis Opera. Tradução do grego: Projeto Perseus, 1903. [607c-d] Oxford University Press. 1903. Disponível em: <http:// www.perseus.tufts.edu/hopper/text?doc=Perseus:text:1999.01.0167> Acesso em: 05/07/2017.

. Timeu-Crítias: texto estabelecido e anotado por John Burnet; tradução, apresentação e notas de Rodolfo Lopes. Coimbra: Imprensa da Universidade de Coimbra, 2011. PERSEUS. A de Glaucos olhos - Um dos Epítetos de Atenas. 2018. Disponível em: <http://www.perseus.tufts.edu/hopper/text?doc=Perseus:text:1999.04.0057:entry=g laukw=pis $>$ Acesso em: 31/10/2018.

ROJAS Blanco, Clara Eugenia. La perspectiva de gênero: noema y nóesis de la epistemología feminista Nóesis. Revista de Ciencias Sociales y Humanidades, vol. 18, núm. 35, enero-junio, 2009, pp. 17-33 Instituto de Ciencias Sociales y Administración Ciudad Juárez, México. Disponível em: <http://www.redalyc.org/articulo.oa?id=85916757004> Acesso em 15 de agosto de 2018.

SAFATLE, Vladimir. 0 amor é mais frio que a morte: negatividade, infinitude e indeterminação na teoria hegeliana do desejo. Kriterion, Belo Horizonte, v. 49, n. 117, p. 95-125, 2008. Disponível em: <http://www.scielo.br/scielo.php?script=sci arttext\&pid=S0100-512X2008000100006\&lng=en\&nrm=iso >. Acesso em: 31/10/2018; <http://dx.doi.org/10.1590/S0100-512X2008000100006>.

SAFO, de Lesbos. Poemas e Fragmentos. Edição bilíngue. Tradução de Joaquim Brasil Fontes. São Paulo: Iluminuras, 2003. p. 25, 27, 47, 51 e 52.

MARTON, Scarlett. Nietzsche. Das forças cósmicas aos valores humanos. São Paulo: Editora Brasiliense, 1990.

VELOSO, Caetano. A língua. In: Velô. 1984. Disponível em: <https://www.letras.mus. br/caetano-veloso/44738/> Acesso em: 31/10/2018.

Revista Páginas de Filosofia, v. 9, n. 2, p. 19-34, jul.-dez. 2020 